\title{
journal
}

\section{Study of the dehydroxylation-rehydroxylation of pyrophyllite}

\begin{tabular}{|r|l|}
\hline Journal: & Journal of the American Ceramic Society \\
\hline Manuscript ID: & Draft \\
\hline Manuscript Type: & Article \\
\hline Author: & \\
\hline Complete List of Authors: & $\begin{array}{l}\text { Perez-Rodriguez, Jose; ICMSE } \\
\text { Duran, Adrian } \\
\text { Sanchez-Jimenez, Pedro; University of Colorado } \\
\text { Franquelo, Maria; ICMSE } \\
\text { Perejon, Antonio; ICMSE } \\
\text { Pascual, Jose; Malaga University } \\
\text { Perez-Maqueda, Luis A.; C.S.I.C.-Universidad de Sevilla, Instituto } \\
\text { de Ciencia de Materiales de Sevilla }\end{array}$ \\
\hline Keywords: & silicates, spectroscopy, thermal analysis, aluminosilicates, kinetics \\
\hline
\end{tabular}

\section{今 scholarONE \\ Manuscript Central}




\title{
Study of the dehydroxylation-rehydroxylation of pyrophyllite
}

\author{
J.L. PereZ-RodrigueZ ${ }^{1}$, A. DuraN ${ }^{1,2}$, P.E. SÁnCheZ JimÉneZ ${ }^{1,3}$, M.L. FranQuelo ${ }^{1}$, \\ A. Perejón ${ }^{1}$, J. PASCUAL $^{4}$, L.A. PÉREZ-MaquedA ${ }^{1 *}$ \\ ${ }^{1}$ Instituto de Ciencia de Materiales de Sevilla (C.S.I.C. - Univ.Sevilla). c/ Americo Vespucio, 49. \\ 41092 Seville, Spain. \\ ${ }^{2}$ Centre de Recherche et de restauration des musées de France-CNRS UMR 171, Palais du Louvre, \\ Porte des Lions, 14 Quai François Mitterrand, 75001 Paris, France \\ ${ }^{3}$ Department of Mechanical Engineering. Engineering Center - ECME 150 \\ University of Colorado at Boulder, Boulder CO 80309-0427, USA \\ ${ }^{4}$ Depart. de Ingeniería Civil, Materiales y Fabricación, ETSII, U. de Málaga. 29013 Málaga, Spain.
}

\begin{abstract}
.
It has been observed that the partially or totally dehydroxylated pyrophyllite suffers a partial reversible rehydroxylation when cooled down at room temperature. This rehydroxylation was substantiated by thermogravimetric measurements by a mass increase, while IR spectroscopic studies have shown that during the rehydroxylation the intensity of some $\mathrm{OH}$ bands increase as two new bands appear. This rehydroxylation process is also very much influenced by the particle size of the pyrophyllite.
\end{abstract}

Keywords- Pyrophyllite, Particle Size, Dehydroxylation, Rehydroxylation, Thermogravimetry, FTIR Spectroscopy, X-ray diffraction,

\footnotetext{
This work was financially supported by MICINN project of Spain (2008-06619/MAT) and Consejería de Innovación y Ciencia, Junta de Andalucia, Spain (TEP-03002)

*Author to whom correspondence should be addressed. e-mail: maqueda@cica.es
} 


\section{INTRODUCTION}

Pyrophyllite is a 2:1 aluminosilicate $\left[\mathrm{Al}_{2} \mathrm{Si}_{4} \mathrm{O}_{10}(\mathrm{OH})_{2}\right]$ clay that in nature appears in beds with different proportions of pure pyrophyllite, maximum about $90 \%$, accompanied by other minerals such as kaolinite, quartz, mica, etc. Pyrophyllite has a dioctahedral layer structure with an octahedrally coordinate $\mathrm{Al}$ ions sheets in-between two sheets of $\mathrm{SiO}_{4}$ tetrahedra. ${ }^{1-3}$ Pyrophyllite has many industrial applications, mostly due to its good technological properties produced by thermal treatment. Thus, it has been mainly used as a raw material in glass, ceramic and refractory industries, for applications such as insulating firebrick or foundry specialities and also in various white-ware bodies. ${ }^{4,5}$ New applications, such as its use in geopolymers, have been also recently reported. ${ }^{6}$ The technological application of pyrophyllite, demands their proper workability, which may be improved by a decrease in particle size..$^{7-19}$ Due to its interest, the thermal dehydroxylation of pyrophyllite has received significant attention in literature. ${ }^{17,20-36}$ Wardle and Brindley ${ }^{3}$ have suggested that the dehydroxylated pyrophyllite consists of 5-coordinate, distorted, trigonal bipyramidal $\mathrm{AlO}_{5}$ structural units in the aluminium oxide layer sandwiched between two distorted tetrahedral silica layers. ${ }^{27} \mathrm{Al}$ NMR-MAS studies have shown the 6-coordinated Al in pyrophyllite change their structural arrangement to 5-coordinate $\mathrm{Al}$ in dehydroxylated pyrophyllite. ${ }^{21,22,37}$ It has been reported that grinding of pyrophyllite favours the formation of pentacoordinated $\mathrm{Al}{ }^{32} \cdot{ }^{29} \mathrm{Si}$ MAS-NMR data have confirmed that the tetrahedral $\mathrm{SiO}_{4}$ sheets remain unchanged, indicating that dehydroxylated pyrophyllite maintains the 2:1 layer structure. ${ }^{22}$ The formation of 5-coordinate aluminium sites in dehydroxylated pyrophyllite is consistent with a homogeneous reaction of the adjacent $\mathrm{OH}$ groups to liberate water and the formation of a bridging oxide midway between adjacent aluminium atoms. ${ }^{27}$ 
The dehydroxilated pyrophyllite may suffer a rehydroxylation process. Heller et al. ${ }^{38}$ have shown that infrared spectrum of rehydroxylated pyrophyllite provides evidence for the formation of layers that may be composed of regions with pyrophyllite-like structure associated with dehydroxylated materials. Rehydroxilation of pyrophyllite appears to be a function of particle size, since coarsely crystalline dehydroxylated samples showed little or not rehydroxylation after steam treatment whereas dehydroxylated 100-mesh material ground under a vibratory mill was rehydroxylated to the extent of 48 per cent. The grinding of the pyrophyllite produces structural alteration ${ }^{30,39}$ that may affect the rehydroxilation. The rehydroxylation of pyrophyllite involved heating samples in water vapour or left at room temperature for several months..$^{20,38,40-42}$ The structural transformation of other clay minerals such as illite, montmorillonite, glauconite and celadonite during dehydroxylationrehydroxylation reaction has been also studied by Muller et al. ${ }^{29}$

Nevertheless, Wang et al. ${ }^{33}$ have recently found, using infrared spectroscopy, that the dehydroxylation of pyrophyllite in the temperature range $550-900{ }^{\circ} \mathrm{C}$ is characterized by a decrease in the intensity of the $\mathrm{OH}$ signals and phonon bands of pyrophyllite as well as the appearance of extra signals at 3690 and $3702 \mathrm{~cm}^{-1}$, that they attribute to an intermediate partially dehydroxylated phase. Thus, these authors suggested that the dehydroxylation of pyrophyllite is a two-stage process with a defined intermediate stage. Based on these observations, it has been theoretically proposed the presence of different possible intermediates. ${ }^{43,44}$ Nevertheless, it has not been considered that pyrophyllite samples after annealing were cooled down, ground and dried at $110^{\circ} \mathrm{C}$ during $12 \mathrm{~h}$. Thus, the contact with laboratory atmosphere may produce rehydration of the samples and be responsible of the intermediates phases that cannot be necessarily attributed to the heating process. 
The thermally-induced dehydroxylation and later rehydroxylation of pyrophyllite remains only partially understood. The aim of this study is to investigate the thermallyinduced dehydroxylation and rehydroxilation of pyrophyllite paying special attention to the effect of particle size.

\section{Experimental Procedure}

\section{(1) Materials}

The studied sample was a phyrophyllite from Zalamea la Real, Spain, that is a mixture of pyrophyllite, kaolinite, mixed layer illite-smectite and illite, and a small content of rutile and quartz. This pyrophyllite was purified following a procedure previously described in literature. $^{45,46}$ After this treatment the sample was constituted by pure pyrophyllite accompanied by a small proportion of rutile. This sample was selected because it has already different particles sizes, while the mechanical treatment required by other natural pyrophyllite

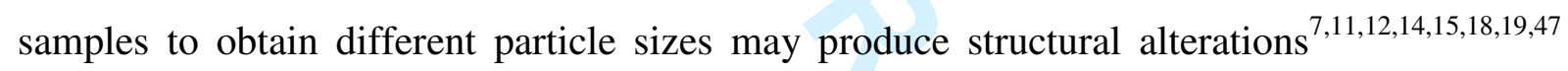
and, therefore, are not suitable for the present study. The different fractions were separated using an aqueous gravity sedimentation procedure for separation of the coarser fractions and a centrifugation procedure for collecting the smallest ones. ${ }^{48}$ Thus, several fractions with different particle sizes, i.e. $20-40 \mu \mathrm{m}, 10-20 \mu \mathrm{m}, 5-10 \mu \mathrm{m}, 2-5 \mu \mathrm{m}$ and $<1 \mu \mathrm{m}$ were obtained.

\section{(2) Thermal heating}

Thermal treatments of pyrophyllite samples with different particle sizes were carried out between 500 and $1000^{\circ} \mathrm{C}$ for periods of 1 hour and 5 days in a tubular furnace (carbolite furnaces type RHF 1600, Hope Valley, UK). 


\section{(3) Thermogravimetric study}

Thermogravimetric analyses (TG) were carried out with an automatic thermal analyser system (model TG/DTA 6300, SII Nanotechnology, Japan). Experiments were performed in static air at a heating rate of $10^{\circ} \mathrm{C} \min ^{-1}$. Samples were maintained in an oven at $110^{\circ} \mathrm{C}$ overnight before the thermal analysis experiments to remove any hydration water.

Dehydroxylation-rehydroxylation cycles in a water saturated air flow were performed in a simultaneous thermal analysis instrument (model Q600, TA instruments, New Castle, DE).

\section{(4) Kinetic analysis}

The activation energy of the dehydroxylation was obtained by means of the isoconversional method. ${ }^{49,50}$ The method is based in the following equation:

$$
\ln \left(\frac{d \alpha}{d t}\right)_{\alpha}=C_{\alpha}-\frac{E_{\alpha}}{R T_{\alpha}}
$$

being $\alpha$ the reacted fraction (a parameter that changes with the reaction from 0 before the process has started to 1 when it is totally finished), $(\mathrm{d} \alpha / \mathrm{dt})_{\alpha}$ the reaction rate at a particular value of $\alpha, R$ the gas constant and $C_{\alpha}, E_{\alpha}$ and $T_{\alpha}$ the values of a constant, activation energy and temperature for each value of $\alpha$. Thus, the values of the activation energy can be determined from a set of thermogravimetric curves obtained under different linear heating rates. The procedure implies of plotting the values of $\ln (\mathrm{d} \alpha / \mathrm{dt})_{\alpha}$ as a function of $1 / T_{\alpha}$, in such a way that the activation energy is obtained directly from the slope of the resulting line. This method allows determining the activation energy of the process as a function of the reacted fraction from a series of experimental curves obtained under different linear heating rate conditions, without any assumption or previous knowledge about the kinetic model obeyed by the solid-state reaction. 


\section{(5) X-ray diffraction analysis}

Diffraction patterns were obtained using a diffractometer (model, X'PERT PRO, PANalytical, Almelo, The Netherlands) at $40 \mathrm{kV}$ and $40 \mathrm{~mA}$ with $\mathrm{CuK \alpha _{1 }}$ radiation, with a HTK 1200 high temperature chamber and Philips X'Celerator detector.

\section{(6) IR spectroscopy study}

Two different IR spectroscopy measurements were performed in the samples. Thus, temperature-programmed diffuse reflectance infrared Fourier transform spectroscopy (model Nexus FT-IR, Thermo-Nicolet, Newington, NH) was used for collecting spectra under in-situ conditions of heating. Only a few of milligrams of these samples were used for these measurements, and heating was performed in static air. No $\mathrm{KBr}$ was used for the preparation of the sample. Additionally, for room temperature IR measurements, samples of $3 \mathrm{mg}$ of fine samples powders after heating at different temperatures were thoroughly mixed with $900 \mathrm{mg}$ of dry $\mathrm{KBr}$ powder; $200 \mathrm{mg}$ of the sample/matrix mixtures were pressed into disc shaped pellets at room temperature under vacuum. After this, pellets were heated for 24 hours at $110^{\circ} \mathrm{C}$ to remove adsorbed water. Measurements were performed between 400 and $4000 \mathrm{~cm}^{-1}$ with a spectrometer with a DTGS detector coupled with a $\mathrm{KBr}$ beam splitter (model Nicolet 510, Thermo-Nicolet, Newington, NH). A total of 200 scans with an instrumental resolution of $4 \mathrm{~cm}^{-1}$ were collected for each spectrum. Commercial software OMNIC and PEAK FIT were used for data analysis. Integrated absorbance was obtained by curve-fitting, using the secondary derivative method with Gaussian functions and linear baselines. 


\section{Results and Discussion}

Pyrophyllite minerals are classically identified as trans-vacant with a dehydroxylation maximum between 550 and $680^{\circ} \mathrm{C} .^{3,17,29,30,51,52}$ However, some authors identified up to three kinds of pyrophyllite populations. ${ }^{34,53,54}$ The first one identified as a trans-vacant structure showed a DTG dehydroxylation peak with a maximum temperature near $650^{\circ} \mathrm{C}$. The second one identified as a cis-vacant structure showed a DTG dehydroxylation peak at about $880^{\circ} \mathrm{C}$. The third one attributed to cis- and trans- mixture or interestratification of pyrophyllite phases showed two dehydroxylation effects.

Figure 1 displays the thermogravimetric curves in the temperature range $250-950{ }^{\circ} \mathrm{C}$ as obtained for the purified pyrophyllite sample at different heating rates. The curves show only one step with a resulting mass loss percentage (4.95\%) corresponding to the release of structural $\mathrm{OH}$ (dehydroxylation) of an ideal pyrophyllite with a DTG dehydroxylation peak with a maximum temperature about $650^{\circ} \mathrm{C}$. These results are in agreement with only a vacant type in the structure of the sample selected for this work. It is quite clear from Fig. 1 that the thermal dehydroxylation of pyrophyllite is very much affected by the heating rate. Thus, thermal dehydroxylation temperature increases upon increasing heating rate. This behaviour is characteristic of a kinetically driven process. Kinetic analysis of curves in Fig. 1 has been conducted by means of the differential isoconversional method. The resulting values for the activation energy are displayed in Fig. 2 versus the reacted fraction. Results in Fig. 2 shows that the activation energy values are independent of the reacted fraction and, therefore, an unique activation energy of $224 \pm 16 \mathrm{~kJ} \mathrm{~mol}^{-1}$ describes the entire dehydroxylation process. In order to substantiate the effect that particle size may have in the thermal dehydroxylation of pyrophyllite, thermal analysis has been performed on samples of different particle size 
separated from the same pyrophyllite sample. Fig. 3 shows the thermogravimetric traces obtained for different fractions $(<1 \mu \mathrm{m} ; 5-10 \mu \mathrm{m} ; 10-20 \mu \mathrm{m} ; 20-40 \mu \mathrm{m})$. It is quite clear from this figure that the particle size has an important influence on the temperature of the dehydroxylation. Thus, smaller particles dehydroxylate at considerable lower temperatures than larger ones.

High-temperature X-ray diffraction is also a suitable method for studying the thermal dehydroxylation of pyrophyllite. Thus, Fig. 4a displays the diffraction pattern at room temperature for the $<1 \mu \mathrm{m}$ pyrophyllite sample in the range $27.5^{\circ}-29.75^{\circ}$ of $2 \theta$. In this range, only a single diffraction peak is recorded at $28.5^{\circ}(\mathrm{d}=3.13 \AA)$ that corresponds to the 003 peak of the pyrophyllite. As temperature increases, the intensity of this peak decreases, while a new peak corresponding to dehydroxylate pyrophyllite is recorded at $29^{\circ}(\mathrm{d}=3.08 \AA)$, eventually, at $640^{\circ} \mathrm{C}$, the peak corresponding to pyrophyllite disappears and only that of dehydroxylated pyrophyllite is detected (Fig. 4b). In any case no other diffraction peaks were observed during the dehydroxylation that could be attributed to intermediate phases. The reacted fraction of the dehydroxylation can be determined from the ratio of intensities of the two diffraction peaks. Thus, Fig. 5 includes the plots of the reaction fraction as a function of temperature for the $<1 \mu \mathrm{m}$ and $20-40 \mu \mathrm{m}$ fractions under linear heating rate conditions. As it can be seen from this figure, the behaviour is quite similar to that reported by thermogravimetric method. Thus, smaller particles dehydroxylate at much lower temperature than larger ones. Fig. 6 displays the evolution of the reaction fraction with time for the same two fractions of Fig. 5 but under isothermal conditions $\left(\mathrm{T}=520^{\circ} \mathrm{C}\right)$. In this latter case, the smaller particles are totally dehydroxylated in less than 1 hour while the larger ones, even after $40 \mathrm{~h}$, are not totally dehydroxylated. 
Figure 7 displays the temperature-programmed diffuse reflectance infrared spectroscopy measurements for the $<1 \mu \mathrm{m}$ fraction at different temperatures in the spectral range of wavenumbers from 3725 to $3600 \mathrm{~cm}^{-1}$. For the spectrum recorded at room temperature (Fig 7a) only a band at $3675 \mathrm{~cm}^{-1}$ is observed in this spectral range, assigned to $\mathrm{Al}_{2} \mathrm{OH}$ stretching mode due to the interaction between $\mathrm{OH}$ and $\mathrm{Al}^{55}$ The presence of a single band in this spectral range could be attributed to a trans-vacant structure unlike the partially cis- and transvacant structure that shows two OH-stretching bands $\left(3674\right.$ and $\left.3668 \mathrm{~cm}^{-1}\right){ }^{26}$ At $550^{\circ} \mathrm{C}$ (Fig. $7 b$ ), the band at 3675 is broadened and shifted at $3660 \mathrm{~cm}^{-1}$. As the sample is cooled down at room temperature and maintained at room conditions during twelve hours, the spectra (Fig. 7c) shows not only the typical band of pyrophyllite at $3675 \mathrm{~cm}^{-1}$, but two extra bands at 3690 $\mathrm{cm}^{-1}$ and at $3702 \mathrm{~cm}^{-1}$ that were not observed in the original pyrophyllite neither at $550{ }^{\circ} \mathrm{C}$. Therefore, these two new bands that appear after cooling and maintaining the sample a room temperature for several hours, and were not present in the IR spectra of the sample registered a $550^{\circ} \mathrm{C}$, could be attributed to a rehydroxylation process and not to a dehydroxylation process as was assigned by Wang et al. ${ }^{33}$

In order to study the effect of particle size and dehydroxylation temperature in the rehydroxylation of pyrophyllite, a set of samples with different particle sizes $(<1 \mu \mathrm{m}, 2-5 \mu \mathrm{m}$, 5-10 $\mu \mathrm{m}, 10-20 \mu \mathrm{m}$ and 20-40 $\mu \mathrm{m}$ ) were at first heated for one hour at different temperatures, then cooled at room temperature and maintained at room conditions during twelve hours, and finally the FTIR spectra were recorded at room temperature. The intensity of the $\mathrm{OH}$ absorption bands at 3675,3690 and at $3702 \mathrm{~cm}^{-1}$ for the different particle sizes and dehydroxylation temperatures are shown in Figs. 8, 9 and 10, respectively. These figures show a decrease in the intensity of the three absorption bands in the range of temperature below $600{ }^{\circ} \mathrm{C}$ for the $<1 \mu \mathrm{m}$ fraction and below $700^{\circ} \mathrm{C}$ for the other fractions. This decrease in 
band intensity is followed of an increase in the range up to $750{ }^{\circ} \mathrm{C}$ and again of a decrease in the range $750-900{ }^{\circ} \mathrm{C}$. At $900{ }^{\circ} \mathrm{C}$ rehydroxylation is hindered.

In order to follow the dehydroxylation-rehydroxylation process under in situ conditions of heating, thermogravimetric experiments were performed in water saturated air flow. Thus, temperature was increased from room temperature to $750^{\circ} \mathrm{C}$ at $10{ }^{\circ} \mathrm{C} \mathrm{min}^{-1}$, then cooled down at room temperature at $10{ }^{\circ} \mathrm{C} \mathrm{min}^{-1}$, and finally maintained at this temperature for five hours while the sample was maintained under a flow of water saturated air. The entire cycle was repeated several times. Fig. 11a shows the resulting curves for the $<1 \mu \mathrm{m}$ sample and Fig. 11b shows a detail of one of the cycles. In the first heating cycle, the dehydroxylation of the material takes place in the temperature range from about $450{ }^{\circ} \mathrm{C}$ to $645{ }^{\circ} \mathrm{C}$ with a $5.95 \%$ mass loss, while in the range from $645^{\circ} \mathrm{C}$ to $750{ }^{\circ} \mathrm{C}$, no further mass loss is observed. As temperature decreases from $750^{\circ} \mathrm{C}$ to room temperature, a mass increase is recorded; this mass increase continues at room temperature but at a smaller rate. The total amount of mass gain of the dehydroxylated sample is about $1.6 \%$. When the sample is again heated, water is released in two steps clearly discriminated in the DTG signal, one from room temperature to $370{ }^{\circ} \mathrm{C}$ and another from $370{ }^{\circ} \mathrm{C}$ to $750{ }^{\circ} \mathrm{C}$, that correspond to $1.01 \%$ and $0.59 \%$ mass loss, respectively. The low temperature mass loss could be attributed to the release of hydration water, while the one at higher temperature could be assigned to the dehydroxylation of the rehydroxylated pyrophyllite. Thus, the dehydroxylated pyrophyllite suffers hydration and a partial rehydroxylation. This partial rehydroxylation is reversible, as observed in the different cycles of Fig. 11a. A similar behaviour was observed in terms of dehydroxilationrehydroxylation for other pyrophyllite fractions, although the amount of rehydration and rehydroxylation were affected by the particle size. Thus, for the larger fraction, i.e. $20-40 \mu \mathrm{m}$, the total amount of mass gain of the dehydroxylated sample is about $0.4 \%$, in such a way that 
the rehydration correspond to $0.32 \%$ and the rehydroxylation to $0.08 \%$. The maximum temperature used for the dehydroxylation cycles also plays an important role in the amount of water gained during the cooling (Fig. 12). Thus, the maximum mass gain is obtained for 750 ${ }^{\circ} \mathrm{C}$, similarly to the IR study that showed the highest intensity of the $\mathrm{OH}$ bands for the sample previously heated at such temperature (Figs. 8-10).

\section{Conclusions}

It has been observed that the dehydroxylation of pyrophyllite is a kinetically driven process with an activation energy of $224 \pm 16 \mathrm{~kJ} \mathrm{~mol}^{-1}$. The process is very much affected by the particle size of the original pyrophyllite. Thus, smaller particles dehydroxylate at much lower temperature than larger particles. It has been also observed that the totally or partially dehydroxylated pyrophyllite suffers hydration and partial rehydroxylation when cooled down at room temperature. This dehydroxylation-rehydroxylation process is reversible as observed when the sample is heated and cooled in cycles. The particle size also plays an important role in the rehydroxylation process, in such a way that the rehydroxylation is more important in smaller particles than in the larger ones.

\section{References}

${ }^{1}$ S. W. Bailey, "The Status of Clay Mineral Structures," Clays and Clay Minerals, 14 1-23 (1966).

${ }^{2}$ J. H. Rayner and G. Brown, "Structure of Pyrophyllite," Clays and Clay Minerals, 25 73-84 (1966). 
${ }^{3}$ R. Wardle and G. W. Brindley, "Crystal-Structures of Pyrophyllite, 1tc, and of Its Dehydroxylate," American Mineralogist, 57[5-6] 732-\& (1972).

${ }^{4} \mathrm{P}$. W. Harben, "The Industrial Minerals Handbook, 2nd Edition. Industrial Minerals Division." Metal Bulletin PLC: London, United Kingdon., (1995).

${ }^{5}$ R. L. Virta, "Talc and Pyrophyllite," American Ceramic Society Bulletin, 84[8] 25-26 (2005).

${ }^{6}$ K. J. D. MacKenzie, S. Komphanchai, and R. Vagana, "Formation of Inorganic Polymers (Geopolymers) from 2 : 1 Layer Lattice Alumino Silicates," Journal of the European Ceramic Society, 28[1] 177-81 (2008).

${ }^{7}$ J. L. Perez-Rodriguez, L. M. S. Delvillar, and P. J. Sanchez-Soto, "Effects of Dry Grinding on Pyrophyllite," Clay Minerals, 23[4] 399-410 (1988).

${ }^{8}$ J. L. Perez-Rodriguez, L. A. Perez-Maqueda, A. Justo, and P. J. Sanchez-Soto, "Influence of Grinding Contamination on High-Temperature Phases of Pyrophyllite," Journal of the European Ceramic Society, 11[4] 335-39 (1993).

${ }^{9}$ P. J. Sanchez-Soto, A. Justo, and J. L. Perez-Rodriguez, "Grinding Effect on Kaolinite Pyrophyllite Illite Natural Mixtures and Its Influence on Mullite Formation," Journal of Materials Science, 29[5] 1276-83 (1994).

${ }^{10}$ S. S. Amritphale and N. Chandra, "Low Temperature Sintering Pyrophyllite Compositions for Wall Tiles," Canadian Ceramics Quarterly-Journal of the Canadian Ceramic Society, 64[4] 241-44 (1995).

${ }^{11}$ P. Uhlik, V. Sucha, D. D. Eberl, L. Puskelova, and M. Caplovicova, "Evolution of Pyrophyllite Particle Sizes During Dry Grinding," Clay Minerals, 35[2] 423-32 (2000). 
${ }^{12}$ S. Yariv and I. Lapides, "The Effect of Mechanochemical Treatments on Clay Minerals and the Mechanochemical Adsorption of Organic Materials onto Clay Minerals," J. Mat. Syn. Proc. , 8[3-4] 223-33 (2000).

${ }^{13}$ E. T. Stepkowska, J. L. Perez-Rodriguez, M. C. J. de Haro, P. J. Sanchez-Soto, and C. Maqueda, "Effect of Grinding and Water Vapour on the Particle Size of Kaolinite and Pyrophyllite," Clay Minerals, 36[1] 105-14 (2001).

${ }^{14}$ M. Erdemoglu and M. Sarikaya, "The Effect of Grinding on Pyrophyllite Flotation," Minerals Engineering, 15[10] 723-25 (2002).

${ }^{15}$ J. Temuujin, K. Okada, T. S. Jadambaa, K. J. D. MacKenzie, and J. Arnarsanaa, "Effect of Grinding on the Leaching Behaviour of Pyrophyllite," Journal of the European Ceramic Society, 23[8] 1277-82 (2003).

${ }^{16}$ L. A. Perez-Maqueda, F. Franco, and J. L. Perez-Rodriguez, "Comparative Study of the Sonication Effect on the Thermal Behaviour of $1: 1$ and $2: 1$ Aluminium Phyllosilicate Clays," Journal of the European Ceramic Society, 25[9] 1463-70 (2005).

${ }^{17}$ L. A. Perez-Maqueda, O. M. Montes, E. M. Gonzalez-Macias, F. Franco, J. Poyato, and J. L. Perez-Rodriguez, "Thermal Transformations of Sonicated Pyrophyllite," Applied Clay Science, 24[3-4] 201-07 (2004).

${ }^{18}$ L. A. Perez-Maqueda, J. L. Perez-Rodriguez, G. W. Scheiffele, A. Justo, and P. J. SanchezSoto, "Thermal Analysis of Ground Kaolinite and Pyrophyllite," J. Therm. Anal., 39[8-9] 1055-67 (1993).

${ }^{19}$ V. Balek, L. A. Perez-Maqueda, J. Poyato, Z. Cerny, V. Ramirez-Valle, I. M. Buntseva, and J. L. Perez-Rodriguez, "Effect of Grinding on Thermal Reactivity of Ceramic Clay Minerals," Journal of Thermal Analysis and Calorimetry, 88[1] 87-91 (2007). 
${ }^{20}$ V. A. Drits, G. Besson, and F. Muller, "An Improved Model for Structural Transformations of Heat-Treated Aluminous Dioctahedral 2:1 Layer Silicates," Clays and Clay Minerals, 43[6] 718-31 (1995).

${ }^{21}$ J. J. Fitzgerald, A. I. Hamza, S. F. Dec, and C. E. Bronnimann, "Solid-State Al-27 and Si-29 Nmr and H-1 Cramps Studies of the Thermal Transformations of the 2:1 Phyllosilicate Pyrophyllite," Journal of Physical Chemistry, 100[43] 17351-60 (1996).

${ }^{22}$ R. L. Frost and P. F. Barron, "Solid-State Si-29 and Al-27 Nuclear Magnetic-Resonance Investigation of the Dehydroxylation of Pyrophyllite," Journal of Physical Chemistry, 88[25] 6206-09 (1984).

${ }^{23}$ S. Guggenheim, Y. H. Chang, and A. F. K. Vangroos, "Muscovite Dehydroxylation - HighTemperature Studies," American Mineralogist, 72[5-6] 537-50 (1987).

${ }^{24}$ J. T. Kloprogge and R. L. Frost, "An Infrared Emission Spectroscopic Study of Synthetic and Natural Pyrophyllite," Neues Jahrbuch Fur Mineralogie-Monatshefte[2] 62-74 (1999).

${ }^{25}$ J. T. Kloprogge, H. Ruan, and R. L. Frost, "Near-Infrared Spectroscopic Study of Synthetic and Natural Pyrophyllite," Neues Jahrbuch Fur Mineralogie-Monatshefte[8] 337-47 (2000).

${ }^{26}$ S. Lantenois, J. M. Beny, F. Muller, and R. Champallier, "Integration of Fe in Natural and Synthetic Al-Pyrophyllites: An Infrared Spectroscopic Study," Clay Minerals, 42[1] 129-41 (2007).

${ }^{27}$ K. J. D. Mackenzie, I. W. M. Brown, R. H. Meinhold, and M. E. Bowden, "ThermalReactions of Pyrophyllite Studied by High-Resolution Solid-State Al-27 and Si-29 Nuclear Magnetic-Resonance Spectroscopy," Journal of the American Ceramic Society, 68[5] 266-72 (1985). 
${ }^{28}$ E. M. Mojares, K. Tomita, and M. Kawano, "Characterization of $2 \mathrm{~m}$ Pyrophyllite Associated with Argillic Alteration in Steam Heated Evironment, Solo, Mabini, Philippines," J. Min. Petrol. Sci., 96 109-19 (2001).

${ }^{29}$ F. Muller, V. Drits, A. Plancon, and J. L. Robert, "Structural Transformation of $2: 1$ Dioctahedral Layer Silicates During Dehydroxylation-Rehydroxylation Reactions," Clays and Clay Minerals, 48[5] 572-85 (2000).

${ }^{30}$ P. J. Sanchez-Soto and J. L. Perez-Rodriguez, "Thermal-Analysis of Pyrophyllite Transformations," Thermochim. Acta, 138[2] 267-76 (1989).

${ }^{31}$ P. J. Sanchez-Soto and J. L. Perez-Rodriguez, "Formation of Mullite from Pyrophyllite by Mechanical and Thermal Treatments," Journal of the American Ceramic Society, 72[1] 154-57 (1989).

${ }^{32}$ P. J. Sanchez-Soto, J. L. Perez-Rodriguez, I. Sobrados, and J. Sanz, "Influence of Grinding in Pyrophyllite-Mullite Thermal Transformation Assessed by Si-29 and Al-27 Mas Nmr Spectroscopies," Chemistry of Materials, 9[3] 677-84 (1997).

${ }^{33}$ L. Wang, M. Zhang, S. A. T. Redfern, and Z. Y. Zhang, "Dehydroxylation and Transformations of the 2:1 Phyllosilicate Pyrophyllite at Elevated Temperatures: An Infrared Spectroscopic Study," Clays and Clay Minerals, 50[2] 272-83 (2002).

${ }^{34}$ L. Wang and Z. Y. Zhang, "Orientating Structure of Hydroxyls in 2:1 Phyllosilicate," Chinese Science Bulletin, 42[4] 321-24 (1997).

${ }^{35}$ M. Zhang, E. K. H. Salje, M. A. Carpenter, J. Y. Wang, L. A. Groat, G. A. Lager, L. Wang, A. Beran, and U. Bismayer, "Temperature Dependence of Ir Absorption of Hydrous/Hydroxyl Species in Minerals and Synthetic Materials," American Mineralogist, 92[8-9] 1502-17 (2007). 
${ }^{36}$ M. Zhang, L. Wang, S. Hirai, S. A. T. Redfren, and E. K. H. Salje, "Dehydroxylation and CO2 Incorporation in Annealed Mica (Sericite): An Infrared Spectroscopic Study," American Mineralogist, 90[1] 173-80 (2005).

${ }^{37}$ P. J. Sanchez-Soto, I. Sobrados, J. Sanz, and J. L. Perez-Rodriguez, "29-Si and 27-Al Magic-Angle-Spinning Nuclear-Magnetic-Resonance Study of the Thermal Transformations of Pyrophyllite," Journal of the American Ceramic Society, 76[12] 3024-28 (1993).

${ }^{38}$ L. Heller, V. C. Farmer, R. C. Mackenzie, B. D. Mitchell, and H. F. W. Taylor, "The Dehydroxylation and Rehydroxylation of Triphormic Dioctahedral Clay Minerals " Clay Minerals Bulletin 556-72 (1962).

${ }^{39}$ P. J. Sanchez-Soto, A. Justo, J. L. Perez-Rodriguez, and E. Morillo, "Structural Alteration of Pyrophyllite by Dry Grinding as Studied by Ir Spectroscopy," Journal of Materials Science Letters, 13[12] 915-18 (1994).

${ }^{40}$ K. Emmerich, "Spontaneous Rehydroxylation of a Dehydroxylated Cis-Vacant Montmorillonite," Clays and Clay Minerals, 48[3] 405-08 (2000).

${ }^{41}$ R. E. Grim, "Clay Mineralogy." McGraw-Hill: New York, (1968).

${ }^{42}$ R. C. Mackenzie, "The Differential Thermal Investigation of Clays," Vol. 2. Mineralogical Society: London, (1957).

${ }^{43}$ E. Molina-Montes, D. Donadio, A. Hernandez-Laguna, and C. I. Sainz-Diaz, "Dft Research on the Dehydroxylation Reaction of Pyrophyllite - 2. Characterization of Reactants, Intermediates, and Transition States Along the Reaction Path," Journal of Physical Chemistry A, 112[28] 6373-83 (2008).

${ }^{44}$ E. Molina-Montes, D. Donadio, A. Hernandez-Laguna, C. I. Sainz-Diaz, and M. Parrinello, "Dft Research on the Dehydroxylation Reaction of Pyrophyllite 1. First-Principle 
Molecular Dynamics Simulations," Journal of Physical Chemistry B, 112[23] 7051-60 (2008).

${ }^{45}$ C. Maqueda, J. L. P. Rodriguez, and A. Justo, "Problems in the Dissolution of Silicates by Acid Mixtures," Analyst, 111[9] 1107-08 (1986).

${ }^{46}$ J. L. Perez-Rodriguez, C. Maqueda, and J. A., "Pyrophyllite Determination in Mineral Mixture," Clays and Clay Minerals, 33 563-66 (1985).

${ }^{47}$ J. L. Perez-Rodriguez, A. Wiewora, V. Ramirez-Valle, A. Duran, and L. A. Perez-Maqueda, "Preparation of Nano-Pyrophyllite: Comparative Study of Sonication and Grinding," Journal of Physics and Chemistry of Solids, 68[5-6] 1225-29 (2007).

${ }^{48}$ M. L. Jackson, "Soil Chemical Analysis. Advanced Course," 2nd ed. by the author: Madison, Wis., (1975).

${ }^{49}$ H. L. Friedman, "Kinetics of Thermal Degradation of Char-Forming Plastics from Thermogravimetry . Application to Phenolic Plastic," Journal of Polymer Science Part C-Polymer Symposium[6PC] 183 (1964).

${ }^{50}$ J. M. Criado, P. E. Sanchez-Jimenez, and L. A. Perez-Maqueda, "Critical Study of the Isoconversional Methods of Kinetic Analysis," Journal of Thermal Analysis and Calorimetry, 92[1] 199-203 (2008).

${ }^{51}$ R. C. Mackenzie, "Differential Thermal Analysis " Vol. 1. Academic Press: London, (1970).

${ }^{52}$ J. Schomburg, "Thermal Investigation of Pyrophyllites," Thermochim. Acta, 93 521-24 (1985).

${ }^{53}$ L. Wang and Z. Y. Zhang, "Principles and Methods of Quantitative Analysis on B-Axis Disorder in 2 : 1 Dioctahedral Phyllosilicate," Chinese Science Bulletin, 42[22] 190812 (1997). 
${ }^{54}$ L. Wang and Z. Y. Zhang, "High-Temperature Phases of Pyrophyllite and Their Evolutionary Characteristics," Chinese Science Bulletin, 42[2] 140-44 (1997).

${ }^{55}$ V. C. Farmer, "The Layer Silicates," pp. 331-63. in The Infrared Spectra of Minerals, Vol. Monograph, 4. Edited by V. C. Farmer. Mineralogical Society, London, 1974. 


\section{FIGURE CAPTIONS}

Fig.1.- TG (a) and DTG (b) traces for the purified pyrophyllite sample at different heating rates.

Fig.2.- Values of the activation energy of the process as a function of the reacted fraction $(\alpha)$ for the thermal dehydroxylation of the purified pyrophyllite sample.

Fig.3.- TG (a) and DTG (b) traces for different particle size fractions of pyrophyllite.

Fig.4.- 003 diffraction of $<1 \mu \mathrm{m}$ fraction in the original pyrophyllite (a) and after heating at 600 'IC during 30 minutes (b).

Fig.5.- Reaction fraction $(\alpha)$ as a function of temperature for the $<1 \mu \mathrm{m}$ (a) and $20-40 \mu \mathrm{m}$ (b) fractions under linear heating rate conditions.

Fig.6.- Reaction fraction as a function of time for the $<1 \mu \mathrm{m}$ (a) and $20-40 \mu \mathrm{m}$ (b) fractions under isothermal conditions $\left(\mathrm{T}=520^{\circ} \mathrm{C}\right)$

Fig.7.- Diffuse reflectance infrared spectra for the $<1 \mu \mathrm{m}$ fraction recorded at different temperatures: a) room temperature, b) during the dehydroxylation at $550{ }^{\circ} \mathrm{C}$, and c) after heating and cooling down at room temperature and maintained at room conditions during twelve hours

Fig.8.- Intensity of $\mathrm{OH}$ absorption band at $3675 \mathrm{~cm}^{-1}$ for samples of different particle size previously heated for one hour at different temperatures, then cooled at room temperature and maintained at room conditions during twelve hours. $(\mathbf{\square})<1 \mu \mathrm{m}$; (X)

2-5 $\mu \mathrm{m} ;(\boldsymbol{\Delta}$ ) 5-10 $\mu \mathrm{m} ;(\bullet)$ 10-20 $\mu \mathrm{m} ;$ (十) 20-40 $\mu \mathrm{m}$.

Fig.9.- Intensity of $\mathrm{OH}$ absorption band at $3690 \mathrm{~cm}^{-1}$ for samples of different particle size previously heated for one hour at different temperatures, then cooled at room temperature and maintained at room conditions during twelve hours. $(\boldsymbol{\square})<1 \mu \mathrm{m}$; $(\mathbf{X})$

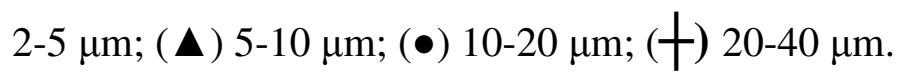


Fig.10.- Intensity of $\mathrm{OH}$ absorption band at $3702 \mathrm{~cm}^{-1}$ for samples of different particle size previously heated for one hour at different temperatures, then cooled at room temperature and maintained at room conditions during twelve hours. $(\mathbf{\square})<1 \mu \mathrm{m}$; (X)

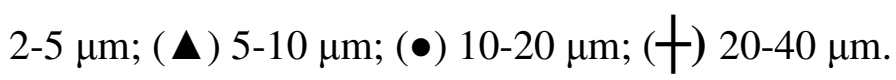

Fig.11.- Cyclic thermogravimetric experiment in water saturated air flow for the $<1 \mu \mathrm{m}$ fraction. Figure (a) shows the entire experiment, while figure (b) shows a detail of one of the cycles. T: temperature, TG: \%mass, DTG: differential mass loss.

Fig.12.- Mass loss of fraction $<1 \mu \mathrm{m}$ previously heated at different temperatures during 1 hour and cooled down at room temperature for $12 \mathrm{~h}$. 